\title{
Reduction of Real Power Loss by Nature Inspired Algorithm
}

\author{
K.Lenin, B.RavindhranathReddy, and M.Suryakalavathi
}

\begin{abstract}
This paper presents American Buffalo algorithm (AB) to solve reactive power dispatch problem. AB algorithm imitates the American buffalo behaviour and their exploration techniques they utilize in the American forests and grasslands. The American buffalo employs its special intellectual, cooperative and independent approach in its exploration for the optimal path to reach the grassland. This endows it to get results faster than some other exploration agents. Proposed AB algorithm has been verified in standard IEEE 30 bus test system. Simulation results show evidently about the improved performance of the proposed algorithm in reducing the real power loss with control variables within the limits.
\end{abstract}

Index Terms - American buffalo, Optimization, Optimal reactive power, Transmission loss.

\section{I.INTRODUCTION}

$\mathrm{U}$ $\mathrm{P}$ to now various methodologies have been applied to solve the Optimal Reactive Power problem. The vital aspect of solving Reactive Power problem is to decrease the real power loss. Earlier several types of mathematical approaches like linear programming, gradient method (Alsac et al., 1973; Lee et al., 1985; Monticelli et al., 1987; Deeb et al., 1990; Hobson, 1980; Lee et al., 1993; Mangoli et al., 1993; Canizares et al., 1996) [1-8] has been used to solve the reactive power problem, but they lack in handling the constraints to reach a global optimization solution.

In the following level several types of evolutionary algorithms (Berizzi et al., 2012; Roy et al., 2012; Hu et al., 2010; Eleftherios et al., 2010) [9-12] has been applied to solve the reactive power problem. In this paper American Buffalo $(\mathrm{AB})$ algorithm has been used to solve reactive power problem. American Buffalo algorithm is comprehensible, stout, operative, and proficient however simple to implement.

K. Lenin is with Department of Electrical \& Electronics Engineering, Jawaharlal Nehru Technological University Kukatpally, Hyderabad, India (e-mail:gklenin@gmail.com)

B. Ravindhranathreddy is with Department of Electrical \& Electronics Eng., Jawaharlal Nehru Tech. University Kukatpally, Hyderabad, India (email:bumanapallibrreddy@yahoo.co.in)

M. Suryakalavathi is with Department of Electrical \& Electronics Engineering, Jawaharlal Nehru Technological University Kukatpally, Hyderabad, India (e-mail: munagala12@yahoo.co.in)
It has noble ability in the exploitation and exploration of the search space. Efficiency of Proposed american buffalo $(\mathrm{AB})$ algorithm has been verified by testing it in standard IEEE 30 bus test system. The simulation results reveals about the best performance of proposed algorithm in minimization of real power loss, when compared to other standard reported algorithms.

\section{A.Real power loss}

\section{II.OBJECTIVE FUNCTION}

The main objective of the reactive power dispatch problem is to reduce the real power loss and can be written in mathematically as follows:

$$
\mathrm{F}=P_{L}=\sum_{\mathrm{k} \in \mathrm{Nbr}} \mathrm{g}_{\mathrm{k}}\left(\mathrm{V}_{\mathrm{i}}^{2}+\mathrm{V}_{\mathrm{j}}^{2}-2 \mathrm{~V}_{\mathrm{i}} \mathrm{V}_{\mathrm{j}} \cos \theta_{\mathrm{ij}}\right)(1)
$$

Where F- objective function, $P_{L}-$ power loss, $g_{k}-$ conductance of branch, $V_{i}$ and $V_{j}$ are voltages at buses $i, j$, Nbr- total number of transmission lines in power systems.

\section{B. Voltage profile augmentation}

To decrease the voltage variation in PQ buses, the objective function $(\mathrm{F})$ can be written mathematically as follows:

$$
\mathrm{F}=P_{L}+\omega_{\mathrm{v}} \times \mathrm{VD}
$$

Where VD - voltage deviation, $\omega_{v^{-}}$is a weighting factor of voltage deviation.

And the Voltage deviation given by:

$$
\mathrm{VD}=\sum_{\mathrm{i}=1}^{\mathrm{Npq}}\left|\mathrm{V}_{\mathrm{i}}-1\right|
$$

Where $\mathrm{N}_{\mathrm{pq}^{-}}$number of load buses.

\section{Equality Constraint}

The equality constraint of the problem is given as power balance equation as follows:

$$
P_{G}=P_{D}+P_{L}
$$

Where $\mathrm{P}_{\mathrm{G}^{-}}$total power generation, $\mathrm{P}_{\mathrm{D}}$ - total power demand.

\section{Inequality Constraints}

Upper and lower bounds on the active power of slack bus $(\mathrm{Pg})$, and reactive power of generators $\left(\mathrm{Q}_{\mathrm{g}}\right)$ are written in mathematically as follows: 


$$
\begin{gathered}
\mathrm{P}_{\text {gslack }}^{\min } \leq \mathrm{P}_{\text {gslack }} \leq \mathrm{P}_{\text {gslack }}^{\max } \\
\mathrm{Q}_{\mathrm{gi}}^{\min } \leq \mathrm{Q}_{\mathrm{gi}} \leq \mathrm{Q}_{\mathrm{gi}}^{\max }, \mathrm{i} \in \mathrm{N}_{\mathrm{g}}
\end{gathered}
$$

Upper and lower bounds of the bus voltage magnitudes $\left(\mathrm{V}_{\mathrm{i}}\right)$ is written by:

$$
\mathrm{V}_{\mathrm{i}}^{\min } \leq \mathrm{V}_{\mathrm{i}} \leq \mathrm{V}_{\mathrm{i}}^{\max }, \mathrm{i} \in \mathrm{N}
$$

Upper and lower bounds of the transformers tap ratios $\left(\mathrm{T}_{\mathrm{i}}\right)$ is written by:

$$
\mathrm{T}_{\mathrm{i}}^{\min } \leq \mathrm{T}_{\mathrm{i}} \leq \mathrm{T}_{\mathrm{i}}^{\max }, \mathrm{i} \in \mathrm{N}_{\mathrm{T}}
$$

Upper and lower bounds of the compensators $\left(Q_{c}\right)$ is written by:

$$
\mathrm{Q}_{\mathrm{c}}^{\min } \leq \mathrm{Q}_{\mathrm{c}} \leq \mathrm{Q}_{\mathrm{C}}^{\max }, \mathrm{i} \in \mathrm{N}_{\mathrm{C}}
$$

Where $\mathrm{N}$ is the total number of buses, $\mathrm{N}_{\mathrm{g}}$ is the total number of generators, $\mathrm{N}_{\mathrm{T}}$ is the total number of Transformers, $\mathrm{N}_{\mathrm{c}}$ is the total number of shunt reactive compensators.

\section{III.AMERICAN BUFFALO ALGORITHM}

American Buffalo (AB) algorithm pretends the vigilant sound and anxiety sound - behaviour of American buffalos in its scavenging endeavours. These vigilant and anxiety are the two elementary sounds of the american buffalos with which they are able to organize themselves to explore for food and guard themselves whenever they are attacked. The anxiety sound is used to rally the buffalos to travel on to explore the search space while the vigilant sound expresses the buffalos to stay on to exploit their environment since it is safe and has sufficient pastures. With these sounds, the buffalos are able to optimize their search for food source (Julius Beneoluchi Odili et al., 2015) [13]. The AB is a population-based algorithm in which individual buffalos work together to solve reactive power problem. Each buffalo within the $\mathrm{AB}$ algorithm epitomises an aggregate object containing a number of elements. The American Buffalo algorithm identifies the independent nature of the buffalos and integrates this into the algorithm. This is represented by Equation (10).

$$
\begin{gathered}
c_{k+1}=c_{k}+r_{g 1} a_{1}\left(l o_{\max }-d_{k}\right) \\
+r_{g 2} a_{2}\left(l f_{\max }-d_{k}\right)
\end{gathered}
$$

Where $c_{k}$ and $d_{k}$ represents the exploration and exploitation moves respectively of the kth buffalo $(\mathrm{k}$ $=1,2, \ldots \ldots \ldots . \mathrm{N}) ; r_{g 1}$ and $r_{g 2}$ are learning factors; $a_{1}$ and $a_{2}$ are arbitrary numbers between $[0,1]$; $l o_{\max }$ is the herd's best fitness and $l f_{\max }$ is the individual buffalo's best one.

In the above equation (10), there is an interface of the numerous buffalos with the prominent (best) buffalo at a specific iteration, a comparison with each buffalos best ever location in relative to the target solution as well as a memory of each animals immediate past location. Depending on the result of the equation (10), the animals move on to explore other locations as expressed in equation (11),

$$
d_{k+1}=\lambda\left(c_{k}+d_{k}\right)
$$

Where $\lambda$ is a unit of time. The algorithm starts by initializing the population of animals through sensible distribution of arbitrary locations to each buffalo within the N-dimensional space. After this, the algorithm modernizes each buffalo's fitness and determines the $l f_{\max }$ (individual buffalo's location) and $l o_{\max }$ (the herd's best location) in specific iteration in relation to the optimal solution. If the existing fitness is superior to the individual's maximum fitness $\left(l f_{\max }\right)$, it protects the location vector for the particular buffalo. If the fitness is superior than the herd's overall extreme, it protects it as the herd's maximum $\left(l_{\max }\right)$. Lastly it modernizes the buffalo's position and looks at the subsequent buffalo in the population. At this point, if our global best fitness meets our exit criteria, it ends the run and delivers the location vector as the solution to the given problem. Twofold key equations control the movement of buffalos within the search space and these are Equations (10) and (11). The equation (10) provides the decision to either stay on to exploit the environment further or to travel on to search other areas based on the collective intelligence of the herd after intermingling with each other in a communal decision-making process.

The equation (11) pushes the buffalos to travel on to search other areas based on the consequence of (10) after due consideration of the two competing forces $\left(l o_{\max }, l f_{\max }\right)$. The $\lambda$ parameter which outlines the discrete time interval over which the buffalo must move is usually set to 1.0. The application of these two Equations results in a new location for the buffalos. It should be observed that equation (10) aside from the memory part $\left(c_{k}\right)$, have two other controlling features, namely, the global maximum $\left(l o_{\max }\right)$ and the individual maximum positions $\left(l f_{\max }\right)$ : each defining the representative influence over the animal's location.

The algorithm subtracts the dimensional element $d_{k}$ from the maximum vector and then multiplies this by an arbitrary number $\left(a_{1}, a_{2}\right)$ usually between 0.0 and 0.6 a learning/acceleration parameter $\left(r_{g 1}, r_{g 2}\right)$.Using the arbitrary numbers between 0.0 and 0.6 has been effective in obtaining fast convergence. It should be emphasized that the arbitrary numbers give an amount of arbitrariness in the path to help the animals move throughout the search space. It does this by arbitrarily giving more or less emphasis to the global $\left(l_{\max }\right)$ or individual maximum solutions depending on the need for more exploration or exploitation respectively as the algorithm developments. 
TABLE III

$\mathrm{AB}$ algorithm for solving reactive power problem.
a. Objective function of the problem
b. Initialization: arbitrarily place buffalos to nodes at the solution space
c. Update the buffalo's fitness values using Equation (10)
d. Update the location of buffalo using equation (11)
e. Is $l o_{\max }$ updating if yes, go to next step or else go to $b$
f. If the ending criterion is not met, then go back to algorithm step c
g. Output finest solution.

\section{IV.SIMULATION RESULTS}

Legitimacy of proposed AB algorithm has been confirmed by testing it in IEEE 30-bus, 41 branch system and it has 6 generator-bus voltage magnitudes, 4 transformer-tap settings, and 2 bus shunt reactive compensators.

Bus 1 is taken as slack bus and 2, 5, 8, 11 and 13 are considered as PV generator buses and others are PQ load buses. Control variables limits are given in Table I. In Table II the power limits of generators buses are enumerated.

TABLE I

PRIME VARIABLE LIMITS (PU)

\begin{tabular}{|c|c|c|c|}
\hline $\begin{array}{c}\text { List of } \\
\text { Variables }\end{array}$ & Minimum & Maximum & Type \\
\hline Generator Bus & 0.95 & 1.1 & Continuous \\
\hline Load Bus & 0.95 & 1.05 & Continuous \\
\hline $\begin{array}{c}\text { Transformer- } \\
\text { Tap }\end{array}$ & 0.90 & 1.1 & Discrete \\
\hline $\begin{array}{c}\text { Shunt Reactive } \\
\text { Compensator }\end{array}$ & -0.10 & 0.30 & Discrete \\
\hline
\end{tabular}

TABLE II

GENERATORS POWER LIMITS

\begin{tabular}{|c|c|c|c|c|}
\hline Bus & $\mathbf{P}_{\mathbf{g}}$ & $\mathbf{P}_{\text {gmin }}$ & $\mathbf{P}_{\text {gmax }}$ & $\mathbf{Q}_{\text {gmin }}$ \\
\hline 1 & 96.00 & 49 & 200 & -19 \\
\hline 2 & 79.00 & 18 & 79 & -19 \\
\hline 5 & 49.00 & 14 & 49 & -11 \\
\hline 8 & 21.00 & 11 & 31 & -14 \\
\hline 11 & 21.00 & 11 & 28 & -12 \\
\hline 13 & 21.00 & 11 & 39 & -14 \\
\hline
\end{tabular}

Table III shows the proposed AB methodology efficiently kept the control variables within limits. Table IV list out the overall comparison of the results of optimal solution obtained by various methods. AB is an attempt to develop a user-friendly, effective, efficient, simple-to-application algorithm that will demonstrate exceptional capacity in the exploitation and exploration of the search.

AFTER OPTIMIZATION VALUES OF CONTROL VARIABLES

\begin{tabular}{|l|l|}
\hline Control Variables & AB \\
\hline V1 & 1.0231 \\
\hline V2 & 1.0179 \\
\hline V5 & 1.0186 \\
\hline V8 & 1.0541 \\
\hline V11 & 1.0699 \\
\hline V13 & 1.0387 \\
\hline T4,12 & 0.00 \\
\hline T6,9 & 0.01 \\
\hline T6,10 & 0.90 \\
\hline T28,27 & 0.91 \\
\hline Q10 & 0.10 \\
\hline Q24 & 0.10 \\
\hline Real power loss & 4.2879 \\
\hline Voltage deviation & 0.9081 \\
\hline
\end{tabular}

TABLE IV COMPARISON OF RESULTS

\begin{tabular}{|c|c|}
\hline Techniques & $\begin{array}{c}\text { Real power loss } \\
\text { (MW) }\end{array}$ \\
\hline SGA(Wu et al., 1998) [14] & 4.98 \\
\hline PSO(Zhao et al., 2005) [15] & 4.9262 \\
\hline LP(Mahadevan et al., 2010) [16] & 5.988 \\
\hline EP(Mahadevan et al., 2010) [16] & 4.963 \\
\hline CGA(Mahadevan et al., 2010) [16] & 4.980 \\
\hline AGA(Mahadevan et al., 2010) [16] & 4.926 \\
\hline CLPSO(Mahadevan et al., 2010) [16] & 4.7208 \\
\hline HSA (Khazali et al., 2011) [17] & 4.7624 \\
\hline BB-BC (Sakthivel et al., 2013) [18] & 4.690 \\
\hline Proposed AB & 4.2879 \\
\hline
\end{tabular}

\section{V.CONCLUSION}

In this paper, $(\mathrm{AB})$ algorithm has been successfully applied to solve optimal reactive power dispatch problem. Proposed AB algorithm has been verified in the standard IEEE 30 bus system. Simulation results show the vigour of proposed $\mathrm{AB}$ algorithm in reducing the real power loss. Detailed comparison of results given in table 4 and our proposed approach outperforms all other reported standard algorithm in reduction of real power loss The control variables obtained after the optimization by (AB) methodology are well within the limits. So by keeping the voltage profile within the stipulated limits the real power loss has been reduced by our projected American Buffalo Algorithm.

\section{REFERENCES}

[1] O. Alsac, and B. Scott, "Optimal load flow with steady state security”, IEEE Transaction. Vol.PAS-93, No.3, pp.745$751,1974$.

[2] K.Y. Lee, Y.M. Park, J.L. Oritz, "A united Approach to Optimal Real and Reactive Power Dispatch", IEEE Transactions on power Apparatus and systems, Vol.PAS104, No.5, pp.1147-1153, 1985.

[3] A.Monticelli , M .V.F Pereira, and S. Granville, "Security constrained optimal power flow with post contingency corrective rescheduling", IEEE Transactions on Power Systems, Vol.PWRS-2, No.1, pp.175-182,1987. 
[4] DeebN ,Shahidehpur S.M ,Linear reactive power optimization in a large power network using the decomposition approach. IEEE Transactions on power system, Vol.5, No.2, pp.428-435, 1990.

[5] E. Hobson,"Network Consrained Reactive Power Control Using Linear Programming", IEEE Transactions on Power Systems, Vol.PAS-99, No.4, pp.868-877, 1980.

[6] K.Y. Lee, Y.M Park, and J.L Oritz, "Fuel -cost optimization for both real and reactive power dispatches", IEE Proc. Vol.131, No.3, pp.85-93, 1984.

[7] M.K. Mangoli, and K.Y. Lee, "Optimal real and reactive power control using linear programming", Electr.Power System Research, Vol.26, No.1, pp.1-10, 1993.

[8] C.A. Canizares, A.C.Z.de Souza and V.H. Quintana, "Comparison of Performance Indices for Detection of Proximity to Voltage Collapse", Vol.11, No.3, pp.14411450, Aug 1996.

[9] A.Berizzi, C. Bovo, M. Merlo, and M. Delfanti, "A GA Approach to Compare orpf Objective Functions Including Secondary Voltage Regulation", Electric Power Systems Research, Vol.84, No.1, pp.187- 194, 2012.

[10] P. Roy, S. Ghoshal, and S. Thakur, "Optimal VAR Control for Improvements in Voltage Profiles and for Real Power Loss Minimization Using Biogeography Based Optimization," International Journal of Electrical Power and Energy Systems, Vol.43, No.1, pp.830-838, 2012.

[11] Z. Hu, X. Wang, and G. Taylor, "Stochastic Optimal Reactive Power Dispatch: Formulation and solution method", International Journal of Electrical Power and Energy Systems, Vol.32, No.6, pp.615-621, 2010.

[12] I.A. Eleftherios, P.S. Georgilakis, M.A. Tsili, G.K. Antonios, "Ant Colony Optimisation Solution to Distribution Transformer Planning Problem", Internationl Journal of Advanced Intelligence Paradigms, Vol.2, No.4, pp.316-335, 2010.

[13] J.B. Odili, M.N.M. Kahar, "Numerical Function Optimization Solutions Using the African Buffalo Optimization Algorithm", British Journal of Mathematics \& Computer Science, Vol.10, No.1, pp.1-12, 2015.

[14] Q.H. Wu, Y.J.Cao, and J.Y. Wen. "Optimal Reactive Power Dispatch Using an Adaptive Genetic Algorithm", International Journal of Elect. Power Energy Systems, Vol.20. pp.563-569, Aug 1998.

[15] B. Zhao, C. X. Guo, and Y.J. CAO, "Multiagent-based Particle Swarm Optimization Approach for Optimal Reactive Power Dispatch", IEEE Trans. Power Syst. Vol.20, No.2, pp.1070-1078, May 2005.

[16] Mahadevan. K, Kannan P. S. "Comprehensive Learning Particle Swarm Optimization for Reactive Power Dispatch", Applied Soft Computing, Vol.10, No.2, pp.64152, March 2010.

[17] A.H. Khazali, M. Kalantar, "Optimal Reactive Power Dispatch based on Harmony Search Algorithm", Electrical Power and Energy Systems, vol.33, no.3, pp.684-692, March 2011.

[18] S. Sakthivel, M. Gayathri, V. Manimozhi, "A Nature Inspired Optimization Algorithm for Reactive Power Control in a Power System", International Journal of Recent Technology and Engineering (IJRTE), vol.2, no.1, pp.2933, March 2013.

\section{BIOGRAPHIES}

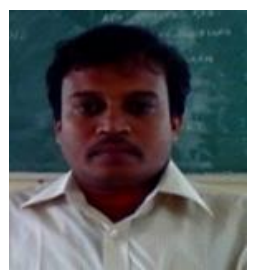

Kanagasabai Lenin has received his B.E., Degree, electrical and electronics engineering in 1999 from university of madras, Chennai, India and M.E., Degree in power systems in 2000 from Annamalai University, TamilNadu, India. Presently pursuing Ph.D., degree at JNTU, Hyderabad, India.

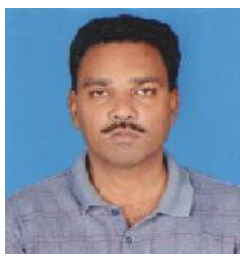

Bhumanapally RavindhranathReddy, Born on 3rd September, 1969. Got his B.Tech in Electrical \& Electronics Engineering from the J.N.T.U. College of Eng., Anantapur in the year 1991. Completed his M. Tech in Energy Systems in IPGSR of J.N.T. University Hyderabad in the year 1997. Obtained his doctoral degree from JNTUA, Anantapur University in the field of Electrical Power Systems. Published 12 Research Papers and presently guiding $6 \mathrm{Ph}$.D. Scholars. He was specialized in Power Systems, High Voltage Engineering and Control Systems. His research interests include Simulation studies on Transients of different power system equipment.

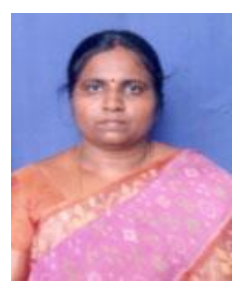

M. Surya Kalavathi has received her B.Tech. Electrical and Electronics Engineering from SVU, Andhra Pradesh, India and M.Tech, power system operation and control from SVU, Andhra Pradesh, India. she received her Ph.D. Degree from JNTU, Hyderabad and Post doc. From CMU - USA. Currently she is Professor and Head of the electrical and electronics engineering department in JNTU, Hyderabad, India and she has Published 16 Research Papers and presently guiding 5 Ph.D. Scholars. She has specialised in Power Systems, High Voltage Engineering and Control Systems. Her research interests include Simulation studies on Transients of different power system equipment. She has 18 years of experience. She has invited for various lectures in institutes. 